\title{
Biography - Wolf H. Fridman, M.D., Ph.D.
}

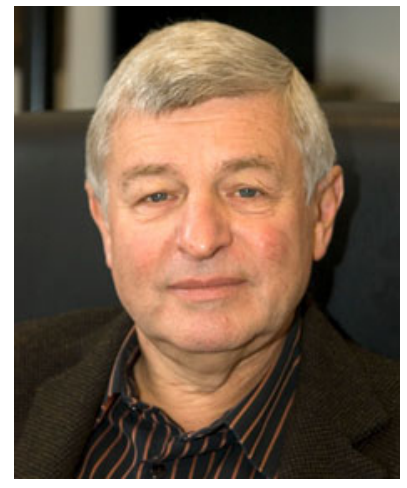

Professor Wolf H. Fridman is a Professor of Immunology at the Paris Descartes University Medical School in Paris, France. He received his $\mathrm{MD}$ and $\mathrm{PhD}$ degrees from the University of Paris. After 10 years in the laboratory headed by Jean Dausset, he created his own laboratory at the Cancer Research Centre in Villejuif in 1976, then moved to Institut Curie in 1983, and is presently the Director of the Cordeliers Research Centre, a joint research structure between INSERM, University Paris Descartes, and University Pierre et Marie Curie. He is also the Head of the Immunology Laboratory of European Hospital Georges Pompidou in Paris.

Dr. Fridman's research interests have been focused around the role of the immune system in controlling human tumors and the biological functions of receptors for $\operatorname{IgG}$ antibodies, both through basic and translational approaches. $\mathrm{He}$, and his team, identified the protein references which trigger the biological functions of the receptors for IgG. In particular, he identified and named the ITIM motif, an inhibitory motif common to many receptors.

His main contributions in cancer immunology stand up to 1969 when he published, with François Kourilsky, the first demonstration of an immune response of the patient to his own cancer, in acute leukemia. He then focused on the analysis of the tumor microenvironment with the demonstration of the beneficial effect of a Th1-oriented immune response to control clinical outcome in cervical cancer. Since 2005, the studies of Jérôme Galon, Franck Pagès, and Wolf H. Fridman have changed the paradigm of host/cancer interactions by demonstrating that the "immune contexture", taking into account the functionality, the location, and the density of the immune infiltrate in colorectal tumors, is the major prognostic factor for human cancers. These findings really open the way for immunebased tools for efficient prognosis and therapy of cancers.

Prof. WH Fridman is a co-author of 367 original peerreviewed publications in journals which include Nature, Science, New England Journal of Medicine, Immunity Journal of Experimental Medicine, Journal of Clinical Investigation, Journal of Clinical Oncology, Gastroenterology, Blood, Proceedings of the Natural Academy of Sciences, Cancer Research, Journal of Immunology, European Journal of Immunology, Oncogene, Clinical Cancer Research, British Journal of Hematology, etc. He is a world leader in the field of human tumor immunology as assessed by his recurrent invitations as a Symposium Speaker to AACR, Keystone, FASEB, and other top international meetings. 